\title{
Exploring Lecturers' Perceptions of Learning Management System: An Empirical Study Based on TAM
}

\author{
http://dx.doi.org/10.3991/ijep.v4i3.3497
}

\author{
W.W. Goh, J. L. Hong and W.Gunawan \\ Taylor's University, Malaysia
}

\begin{abstract}
With the pervasive take-up and presence of digital technologies, learning management system (LMS) is popular for its open accessibility and its interactive nature. Implementation of LMS has become part of the strategic plan in higher education institution to enhance the flexibility in teaching and learning. It is essential to explore the perceptions of users in using the LMS in order to inform stakeholders the positive influencing aspects and improve the negative factors in the future. This study investigates the perception of lecturers in using LMS in term of perceived usefulness and perceived ease of use for teaching purposes. Technology Acceptance Model (TAM) is used as the research framework to design the questionnaire. An online questionnaire was created to address the research questions. The results reveal that lecturers do not react positively towards perceived ease of use of Moodle for teaching. Lecturers treat Moodle as content repository and do not fully utilize the interactive features in Moodle. It was found that usability issues, interaction and communication issues had a negative impact on the lecturers' perception.
\end{abstract}

Index Terms - Educational technology; Electronic learning; Learning management system.

\section{INTRODUCTION}

With the digital revolution, online technologies tool has been widely used in higher education to facilitate some form of co-learning among students and lecturers. Large volume and wide range of information are available online. All the learning materials can be assessed by students and lecturers, at anytime, anywhere. When digital technologies are available in education settings, lecturers have an important role to play to ensure that students are using online technologies in the correct approach.

Higher education (HE) nowadays use learning management system (LMS) to provide $24 / 7$ accessibility to course materials. This technology support lecturers to manage their students' access to courses materials and monitor students' learning activities. It offers a medium for knowledge sharing and acts as a communication tool. Therefore, LMS has created the opportunities for lecturers and students to use digital technologies in educational contexts.

Many HE have adopted LMS to increase quality of teaching and learning, equip users with technological skills, and encourage users to be more interactive. LMS is introduced to deliver course contents to students, allow lecturers to communicate with students and evaluate students' performance. Lecturers must attract the students with appropriate and interesting e-learning content. Hence, they have to take advantage of LMS to make the best of it when providing students with learning materials.

There is a change in teaching practices when online technologies are used as part of innovative teaching approaches. Online technologies have the potential to extend the boundaries of traditional classrooms by providing new opportunities for communication and interaction between students and lecturers. Lecturers need to create a virtual place to allow interaction between students and lecturers. However, for a university to transit from the traditional approach to online based approach, it needs a due consideration as lecturers and students may need some time to adapt to the new environment.

As such, lecturers' acceptance of LMS plays a key role in optimal utilization of LMS in HE. Lecturers' readiness to accept and use LMS would lead to the increase in usage and motivate students to use LMS in class.

When a new e-learning environment is presented, it needs to be adopted by its users. Users' perception can be affected by different factors such as the implementation, end users concern, system adoption, technological reliability and security. It is necessary to consider the individual factors that influence the adoption of LMS in lecturers' perspective. To achieve this, researchers seek to understand the relationship between perceptions about technology (such as PU, PEOU) and usage behavior of lecturers in adopting technology as a teaching tool.

Several researches have been conducted to explore the perceptions of students in using LMS. However, it is acknowledged that little research has been conducted focusing on the perception of lecturers in using LMS for teaching. Thus, to demonstrate the adoption process, we present an empirical study to discover the actual usage of LMS for lecturers in a private higher education institution which recently adopts a LMS (Moodle) and made a conversion from their existing LMS (Blackboard). When a particular LMS with new technology and features is adopted, users need to familiarize themselves with the new changes [1]. For the transition and adoption to be conducted successfully, the various stakeholders need to understand the perceptions of the lecturers in using the LMS as a teaching tool.

The first objective of this research is to explore the perception of lecturers in using LMS in term of perceived usefulness and perceived ease of use for teaching purposes. The second objective of this research is to understand the issues occurred when using LMS and to propose some 
recommendations for future. This research is the extension from [1] that investigated the perceived ease of use and perceived usefulness of students in using Moodle. The contribution is to inform the stakeholders of the university the actual usage of LMS in teaching for lecturers. This research is important to university who plan to integrate new LMS into the curriculum.

This paper is organized as follows: the next section discusses the related work of the study. This is followed by a description of the research design. The results and findings are described based on the research questions. Lastly, discussions and conclusion are discussed.

\section{RELATED WORK}

This section discusses Technology Acceptance Model (TAM), learning management system (LMS), Moodle, and Blackboard in detail. Basic usage, functions and history of Moodle and Blackboard will be discussed further in this section.

\section{A. Technology Acceptance Model (TAM)}

In 1989, Fred Davis [2] developed Technology Acceptance Model (TAM), based on Fishbein and Ajzen [3] theory of reasoned action (TRA). "TAM replaces many of TRA's attitude measures with the two technology acceptance measures - ease of use, and usefulnesss"[3]. TAM that has been extended by Davis consists of perceived ease of use, perceived usefulness, attitude toward using, behavioral intention to use, and actual system use. Fig. 1 illustrates the TAM by Davis.

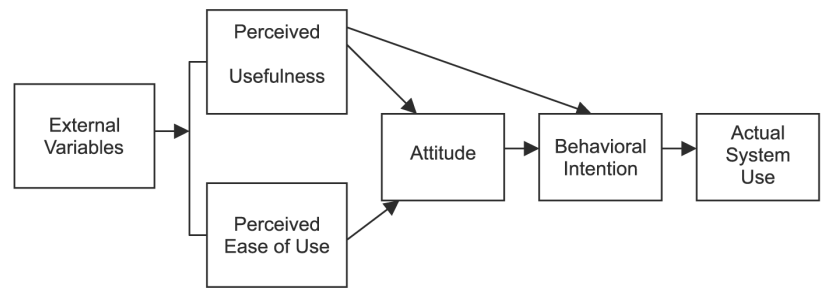

Figure 1. The Technology Acceptance Model

Perceived usefulness (PU) indicates "the degree to which a person believes that the use of a system will improve his/her performance" [2]. PU is defined as "the extent to which a student believes that using the technology will enhance his or her performance. PU can be a strong determinant of intention to use the technology" [4.]

The usefulness of a system in teaching is closely connected to how the lecturers can use the technology to engage students. The usefulness of LMS is the most important factor to conceptualize the quality of learning and teaching in university setting. Lecturers and students will adapt to a new system if it will help them in achieving their purposes. Perceived usefulness is also impacted by perceived ease of use.

Perceived ease of use (PEOU) refers to the "degree to which a person believes that the use of a system will be uncomplicated" [2]. PEOU is defined as "the extent to which a student believes that using the technology will be relatively effortless" [4]. In specific, "it is the evaluation of the degree to which using the technology is free of effort" [2]. If a technology is too complex or difficult to use, users will find the alternative method rather than using the new technology.
TAM is commonly applied to examine users' attitude and behavioral intentions toward the acceptance of technology. It collects opinions of human participants and provides information on using Internet-based teaching platforms. Liu, Liao \& Peng [5] explore the users' acceptance behavior on web-based streaming e-learning. The results show that the media rich interface generated higher levels of perceived usefulness than text-audio and audio-video based presentation. Pardamean, Suparyanto \& Kurniawan [6] confirm that TAM is a valid instrument to measure user acceptance of applying graph theory in the LMS environment. The model advised that when users are presented with a new technology, perceived ease of use and perceived usefulness are the factors that influence their decision about how and when they will use it.

Several studies that explore technology acceptance have shown that TAM is able to predict and explain why users prefer to use the information systems in various disciplines. TAM is extensively employed in information system research because of its understandability and simplicity [7]. TAM has also been applied in e-commerce setting to examine when PEOU affects IT adoption [8]. The study found that TAM is perfectly applicable to business to commerce and business to business systems. TAM also utilized to examine the acceptance of telemedicine technology among physicians. Hu et al. [9] validated that TAM is suitable as an intention-based model to explain and predict user acceptance of computer technology.

TAM has become a vital theoretical tool for ICT in education research areas. Venter, Rensburg \& Davis [10] acknowledged that TAM is widely used to predict technology acceptance in higher education settings by showing ten previous researches that used TAM as a theoretical framework. Nair [11] also agrees that TAM is a robust model which is very effective to assess technology acceptance and predict actual usage of IT tools in teaching and learning.

TAM is also appropriate for other academic setting. For example, Choo \& Rahmat [12] validated TAM in the context of integration of technology in their teaching and learning, [12][13][14] explore the impact of usability of mobile learning in university. The results showed that the usability of the system helps students with their study. There is a significant correlation between students' awareness and motivation towards technology with their readiness for the pedagogical usage of mobile learning.

Previous studies that used TAM to explore the adoption of Moodle are [7][15]. Even though there are studies conducted using TAM to analyze Moodle, the contexts are different. Sumak et al. [7] explore the factors that impact on students' perceptions in the acceptance of Moodle using TAM in the Slovenian context. Hsu \& Chang [16] explore the willingness of students to adopt Moodle for learning. The results revealed the perceived ease of use is the most significant determinant that directly affects the attitude of students in using Moodle. Since TAM has been adapted to higher education, hence, TAM is adopted as a conceptual framework in this study to understand the lecturers' adoption of LMS in term of perceived usefulness and perceived ease of use.

\section{B. Learning Management System (LMS)}

Learning management system (LMS) is a kind of course management application that provides $24 / 7$ accessibility to course materials. It manages students' access to 
courses materials and monitors students' learning activities. LMS is a platform to facilitate the delivery of course materials, knowledge sharing and communication among learners [17]. LMS is not intended to replace the traditional classroom setting but to supplement the traditional lecture with learning materials for students to review and do revision at their own time and place [18]. Lecturers can use LMS to conduct assessment and track students' progress using online quizzes and web 2.0 technologies such as wikis, blogs and discussion forums.

Higher education institutions all over the world promote the use of the LMS, for example they are commonly used in universities in Middle East [19][20][21][22][23], Taiwan [16][24] and the United States [25][26]. Salajan [27] commented that LMS is able to increase the usage and improve the overall student experiences.

LMS provides virtual environments for the teaching and learning process. Based on previous studies, some important benefits of LMS are sharing of knowledge and acting as a communication tool [11][12].

Lecturers not only can use the LMS to share lecture notes and learning resources, they can also promote collaboration and interactivity among students using online discussion and chat rooms. Students are encouraged to discuss, exchange their view points, discuss problems and comment on ideas posted by their peers. Online discussion fosters the engagement of students, enable rich exchanges and community building [28].

Lecturers are creating a more open atmosphere where students are expected to stay connected and keep engage in class discussions. Students are giving the chance to share what they learn with peers using wikis, blogs and discussion board. Literature suggests that the prime role of LMS is to communicate the intended learning activities to students and to act as content repository for the creation and management of resources. It facilitates students' learning experiences via self-assessment quizzes and acts as a kind of online communication tool among lecturers and students.

\section{Blackboard}

Michael Chasen and Matthew Pittinsky developed Blackboard in 1997 [29]. Blackboard is web-based learning management system that assists lecturers to manage and deliver educational courses. Facilities in Blackboard are course content management, asynchronous online communication and online assessments. Lecturers are not only able to share their learning materials with students but also download students' assignments for evaluation purposes. Lecturers can create online quizzes for assessment and use collaborative tools such as blogs, wikis and discussion forum to communicate with students.

There are seven platforms in Blackboard such as: Learn, Transact, Engage, Connect, Mobile, Collaborate and Analytics. Due to the stability and reliability of Blackboard, it is used by more than 70 percent of the U.S. colleges and universities [29]. Cote et al. [30] agreed that Blackboard is an effective platform that supports flexible teaching and learning. Blackboard is a good way to disseminate information to the students. It also assists students in accessing all the learning materials and links that are relevant to support them in their course. Furthermore, Blackboard provided opportunities for student reflection, peer editing and students learning from each other. The results from Cote et al. [30] showed that at first, the students were passive, but eventually they found online discussion forums to be a useful teaching and learning strategy with the focus on reflection and collaborative activities. However, in other study conducted by [18], "course content, course documents, lectures, announcements and quizzes are used more often and are seen as more useful" compared the communication tools in Blackboard. According to Vrielink [31], although Blackboard enhances the quality of education, some lecturers do not see the benefits of it. Several researches have evaluated the effectiveness of Blackboard using TAM in the Western countries [18][26][27]. Faculty members considered the usefulness of Blackboard is the most important factor to conceptualize their quality of teaching [19][26][27]. [18][32][33] measure the students' perception towards Blackboard by employing TAM. Results suggest that students will use the LMS if they see it is useful to them, easy to use and support their needs.

\section{Moodle}

Martin Dougiamas developed the first version of Modular Object-Oriented Dynamic Learning Environment (Moodle) in 2002 [34]. Moodle is an Open Source Learning Management System (LMS). Moodle has a good architecture of implementation, interoperability. It has been adopted by many universities around the world [20]. Moodle is a type of LMS for sharing useful information and learning materials in education settings [35].

Moodle is used as a tool for delivering lecture notes to students, assessing students' performance using assignments and quizzes. It also provides rich collaborative learning communities such as forums, wiki and blogs [7]. Moodle promotes student motivation in carrying out their self-learning, serves as a constructivist tool to allow students' interaction and builds a sense of community [36]. According to Zakaria \& Daud [37], Moodle is a useful tool for delivering content and used to build rich collaborative learning communities.

Moodle is an open source software (OSS) that is provided freely to the public. Even though Moodle is copyrighted but users are free to copy, use and modify the features provided that they must share it with others.

There are more than ten thousands registered Moodle sites. However, since Moodle is an open source, free to download and use, it is hard to know the exact number of Moodle sites that currently used in the market. Moodle is considered flexible, cost savings and easy to customize according to specific course requirements [38]. It has a great extensibility potential and well established. Based on the previous research, students and lecturers are satisfied with the performance and stability of Moodle [38][39][40].

Moodle has been used in teaching various disciplines such as ICT and Science [35], English [21], mathematics [37], problem based learning [41] etc.

Most of the studies are focusing on students' perception in using Moodle for learning [6][7][35][37][42][43][44]. Little research has been conducted to investigate the instructors adoption and implementation of Moodle [23][27][40]. Moodle is chosen as the LMS for this study. Moodle was introduced to the university in early of 2012 as part of the strategic plan to integrate ICT into the curriculum to replace the existing LMS (Blackboard). 


\section{RESEARCH DESIGN}

The qualitative and quantitative approach is adopted in this study to examine the perception of lecturers in using Moodle for teaching. An online questionnaire was created to address the research questions. 43 samples were collected from lecturers from a private educational institution. The questionnaire was put online through the online survey tool using Google Doc. The distribution of the questionnaire to the lecturers was through emails. The purpose of the study was stated in the email. The questionnaire was open for two weeks. A reminder email was sent in the second week to increase the response rate.

Demographic information, questions related to perceived usefulness and perceived ease of use were asked in the questionnaire. The online questionnaire consists of close-ended questions and open-ended questions. Multiple choice items and 5-likert scale items were asked in the close-ended questions. Close-ended questions have important advantages such as providing the respondents with an easy way of indicating their answers and permit the respondents to state the answer categories that were most suitable for their purposes. In this research, open-ended questions were asked to allow respondents to write their personal views in order to receive in depth understanding about the issues under study. All the questions were put in a meaningful order and format according to categories of PU and PEOU. The respondents took no more than 15 minutes to answer the questionnaire. At the end, all the questions were checked for clarity and appropriateness before emailing out. The link to the questionnaire was checked to make sure that it was working properly.

The data from the questionnaire was analyzed after Google Docs generated a summary of the data in the form of graphs.

\section{RESULTS AND FINDINGS}

From the total of 43 respondents, There were 22 male and 21 female participated in the survey. They were aged between 30-45. These lecturers are from various schools in the private higher education institution. However, majority of them are from School of Computing and IT.

From the results of the questionnaire, more than $50 \%$ of the respondents spent less than 30 minutes a day in Moodle. The main reason lecturers spent less than 30 minutes a day in Moodle is because they just uploaded lecture notes, downloaded assignments for marking, posted grades and made announcements. They did not spend time interacting with others.

The results presented in the following section relate to the identified research questions. The research questions are as follows:

1. What is the perceived ease of use of Moodle in the adoption of LMS in teaching from the lecturers' perspective?

2. What is the perceived usefulness of Moodle in the adoption of LMS in teaching from lecturers' perspective?

3. What are the issues faced when using Moodle?

Previous research has shown that TAM is a valid tool to assess the adoption of Moodle among lecturers. The results showed that lecturers have different perceptions of using Moodle for teaching in term of perceived ease of use and perceived usefulness.
The results of this study are divided into two sections. The first section describes the perceived ease of use of Moodle in the adoption of LMS in teaching. In the second section, the perceived usefulness of Moodle in the adoption of LMS in teaching is discussed. Third section elaborates issues faced when using Moodle.

\section{A. The perceived ease of use of Moodle in the adoption of LMS in teaching}

Most of the lecturers did not react positively towards the perceived ease of use of Moodle for teaching. They do not believe that using Moodle is effortless. They find that the interface is not user friendly and dull. They feel that there are too many steps to take in order to get something done. One of the lecturer commented that Moodle has a lot of good functions but it is not organized visible enough. Hence, longer time is spent to complete a task. One of the lecturer voiced out that all the teaching materials could be organized on topic format or weekly format so that the lecture notes listing can be clear for downloading. One of the lecturers responds that they get frustrated when they cannot find the material posted. Majority of the lecturers believe that some level of familiarity is needed and new users need more time for this adjustment and changes. Lecturers feel that email's push notification is helpful because they can be alerted anytime when the students communicate with them using Moodle. It would be great if messages in Moodle are synchronized with university email to encourage speedy response to students.

The findings suggest that the lecturers do not think that their interaction with Moodle is clear and understandable.

This is in contrast with the results found in students' perceived ease of use of Moodle [1], students reacted positively towards using Moodle for learning. The main reason is because students are considered digital natives where using online technologies is part of their life [45].

As mentioned by Prensky [45], lecturers are considered digital immigrants where they do not speak the same language as compared to their students. The learning methods of digital natives are different from their lecturers. They are more technology savvy who receive information really fast and like to parallel process and multi-task. They prefer random access using hypertext. Lecturers who are digital immigrants have little appreciation of these new technologies and therefore need to take more time to explore and familiarize with the LMS.

Some of the respondents' comments and views are stated below:

"Some level of familiarity is needed and need time for adjustment."

"The interface is dull."

"There are too many steps to take in order to get something done."

"It has a lot of good functions but it is not organized visible enough." ed.'

"I get frustrated when I cannot find the material post-

\section{B. The perceived usefulness of Moodle in the adoption of} LMS in teaching

The findings show that majority of the lecturers use Moodle to upload lecture notes (95\%), download assignments $(88 \%)$, create online quizzes $(33 \%)$, upload grades 
$(30 \%)$, post announcements $(84 \%)$ and for a discussion forum $(49 \%)$. Similar to the research conducted for the perceived usefulness by students, lecturers also believe that Moodle elements such as course content, course documents, lecture notes, announcements are more useful and are used more often as compared to those elements such as discussion forum, blogs and wikis.

A significant finding of this study is that majority of the lecturers use Moodle to upload lecture notes and retrieve assignments for marking purposes. Moodle is useful for them for teaching in terms of uploading lecture notes, posting announcements and downloading assignments for marking. Lecturers also treat Moodle as a content repository. This echoes the finding of Goh et al. [1] where the students also use LMS to retrieve their course outline and assignment brief.

Hence, the results indicate that Moodle is a good platform to provide static contents. The lecturers find it useful to embed informative Youtube videos as part of their teaching materials.

$33 \%$ of the lecturers use online quiz as part of their assessment method. According to them, there is a diversified format available ranging from True/False, Multiple Choices to essay writing format to create a lot of different kind of online quiz. However, lecturers feel that it is time consuming to set up online quizzes.

Lecturers do not fully utilize the interactive features and collaborative nature of Moodle. They did not encourage students to use discussion forum, blog, wiki for learning purposes. The same results happened in the research conducted from students' perception [1]. The students' readiness for interaction using learning management system does not exist. The main reason is because lecturers did not inform the students on the usefulness of the interactive features in Moodle. Hence, students used Moodle passively and treat it as content repository only. They did not actively participate in discussion forum.

This shows that lecturers play an important role to use the interactive features in Moodle and encourage students to use it for their learning.

Overall, TAM emphasized the importance of perceived usefulness as the key determinant of user acceptance of a technology. It is found that lecturers perceive Moodle is useful as a learning management system to share all course materials to students but not as an interactive and communicative tool.

\section{"It is good to provide static content."}

"Students are able to submit assignments online and lecturer can comment immediately."

"It was being used to upload lecture notes."

"It helped me to disseminate assignments and other works to the students easily."

"It is great in embedding useful and informative Youtube videos."

\section{Issues faced when using Moodle}

There are a few minor problems faced by lecturers while using Moodle. Lecturers feel that they are unable to customize the layout of Moodle. They feel that some of the fonts are small, too many texts and too little graphics. Sometimes it is slow in systems response time. Another issue is that students complained that the assignments that they have uploaded were missing a few days later. The
ICT personnel need better configurations and fix the bugs because this will cause frustration and interruption to students and lecturers. This instability will make the users less confidence in using Moodle. Furthermore, lecturers voice out that there is no function to provide online comments to students on their assignment submission. One of the lecturers who teach Mathematics expressed that he is unable to type mathematical equations and cannot display mathematical formula in Moodle.

In term of communication, lecturers think that Moodle does not engage students.

Majority of the lecturers use Facebook for online discussion and Q\&A session with students. According to them, Facebook is equipped with mobile notification that enables them to track the online discussion from time to time. Furthermore, students seldom login to Moodle and do not check their university email frequently. It is slow to reach them using Moodle. Hence, lecturers expressed that there is a low interactivity in Moodle as compared to other social networking tools. This is in line with the research conducted by [18]. According to Landry et al. [18], course content factor are used more often and are perceived as more useful than those items that provide course support and communication.

\section{DISCUSSION}

This age group of lecturers is considered as digital immigrants [45]. There is a lack of technological competency in using LMS. Hence, some of them are refuse to integrate new online technology into their teaching. Some of them do not want their course materials to be made widely available for fear that they will be obsolete.

In term of design, the layout could be made more interesting and eye catching. Moodle can be improved to be more direct, simple and user friendly. The font used in Moodle can be enlarged in order that it is easier to read by all the lecturers. ICT personnel and designer need to learn the product and application fast so that they can transmit the latest information to the users and upgrade new design features immediately after it is introduced by Moodle team. ICT personnel and academics need to collectively make an effort to master the use of Moodle and change the students' perception in using Moodle in term of collaboration.

Islam [46] also agrees that in order to maintain user satisfaction, designers should continuously look for opportunities to further improve the LMS platforms that have been implemented. They should focus on making the system easy to use, more accessible and reliable.

Another recommendation is that Moodle should prompt the students automatically through email whenever there are new learning materials or activities that have been uploaded by the lecturers. Furthermore, feedback form on Moodle is important for the users to contact the ICT personnel whenever they face any problem or would like to report any issue as soon as it has happened. Martin \& Kellermanns [47] found that users will find LMS useful when they receive adequate technical support whenever they need help. Support is important especially to new users. According to Lin [40], "many influencing factors may cause instructors to reduce using CMS even quit, such as technical instability or lack of support."

Lecturers would like to receive immediate advice on how to choose and implement appropriate LMS features 
to suit their specific teaching needs of different courses. Therefore, effective staff development programme, hands on training on creating tests, quizzes and using discussion forum is essential to inform the lecturers on the usefulness of the distinctive features in Moodle so that they will use it with their students. For lecturers who are new to Moodle, they need some time to adapt to the new LMS. They have to discover the distinctive features of Moodle before embark on intermediate or advance level. It is important for the lecturers to familiarize themselves with the interactive and collaborative nature of Moodle. Lecturers will have confidence to use LMS when they are comfortable with the features in LMS. [22][23][48] have identified that extensive training and professional development are important to the lecturers because this can help them to develop the necessary skills to use LMS easily. Training is a crucial factor because it has been found to contribute significantly to the success of technology implementation [49]. Furthermore, user guide can be created for popular tasks to help those who face any issues in using the system. Asiri et al. [22] pointed out that if lecturers have a positive attitude towards LMS, they are more likely to be motivated to use LMS.

In term of collaboration and interaction, lecturers can use Moodle as a platform to interact with the students. They should participate actively and interact with students online. Lecturers can lead the students to interact in discussion forum, monitor their activities and provide regular feedback to motivate the students to use Moodle. The students' readiness for using Moodle would be most likely increasing if they are aware of the benefits of it [49]. System developers might have to collaborate with lecturers to design and implement a LMS with good interaction, flexibility and friendly interface and a joyful learning cyberspace to facilitate student's willingness to use LMS [15].

To have a successful e-learning implementation, the authority concerned must emphasize more on the PU [27]. When lecturers believe that if a system is useful to them, they will use it for their benefits or else they will leave it behind. IT policy makers and administrators can conduct usability test with existing users in order to plan for the future improvement of the LMS. It is vital to have continuous improvement or innovation on the system [27]. IT policy makers play an important role to determine the skills required by academics to use Moodle, establish the ICT infrastructure to implement Moodle and to establish the support structures needed. They must be able to facilitate and support its uses within the university.

\section{CONCLUSION}

In summary, lecturers do not believe that using Moodle is effortless. They do not react positively towards the perceived ease of use of Moodle for teaching as compared to students. The main reason is because students are considered digital natives while lecturers are digital immigrants who are new to the digital technologies. Similar to the study conducted regarding students' perceived usefulness for Moodle, lecturers also treat Moodle as a content repository to share static content. However, they do not fully utilize the interactive features in Moodle to collaborate with students. Problems faced by lecturers are usability issues, interaction and communication issues.

The results have implications that are important to different e-learning stakeholders in higher education institutions. It has implication to policy makers and those who involved in IT project implementation. Understanding the perception of lecturers in term of perceived usefulness and perceived ease of use can help the ICT personnel to better design the LMS to suit the teaching curriculum.

The limitation of this study is that the sample size is too small for the findings to be generalized. Therefore, future studies should increase the sample size and focus on different schools and disciplines in the university. Furthermore, longitudinal study is required to provide deeper insights into the change of expectation and attitudes of usage of Moodle since it first implemented.

In conclusion, the findings of this study show that lecturers can have greater engagement in Moodle provided that they have the knowledge on the usefulness and think that Moodle is easy to use for teaching. University should provide plenty of training and workshop in order to provide effective user support and encourage lecturers to use the system. This will provoke the interest and reduce the anxiety of lecturers in using LMS.

\section{REFERENCES}

[1] W. W. Goh, J. L. Hong, and W. Gunawan, "Exploring students' perceptions of learning management system: An empirical study based on TAM," IEEE Teaching, Assessment and Learning for Engineering (TALE) Conference, August 2013.

[2] F. D. Davis, "Perceived usefulness, perceived ease of use, and user acceptance of information technology", MIS Quarterly, 13(3): 319-340, 1989. http://dx.doi.org/10.2307/249008

[3] M. Fishbein, \& I. Ajzen, "Belief, attitude, intention, and behavior: An introduction to theory and research," Reading, MA: AddisonWesley. 1975.

[4] G. A. Jonas and C. Norman, “Textbook websites : user technology acceptance behaviour," Behaviour \& Information Technology, vol. 30, no. 2, pp. 147-159, 2011. http://dx.doi.org/10.1080/ 01449290903353021

[5] S. H. Liu, H. L. Liao, and C. J. Peng, "Applying the technology acceptance model and flow theory to online e-learning users' acceptance behavior," Issues in Information Systems, vol. 6, no. 2 pp. 175-181, 2005.

[6] B. Pardamean, T. Suparyanto, and R. Kurniawan, "Assessment of Graph Theory e-learning utilizing learning management system," Journal of Theoretical and Applied Information Technology, vol. 55, no. 3 pp. 353-358, September 2013.

[7] B. Sumak, M. Hericko, M. Pusnik, and G. Polancié, "Factors Affecting Acceptance and Use of Moodle: An Empirical Study Based on TAM," Informatica, vol. 35, pp. 91-100, 2011.

[8] D. Gefen, and D. Straub, "The relative importance of Perceived Ease of Use in IS Adoption: A study of e-commerce Adoption," Journal of the Association for Information Systems, vol. 1, no. 8 pp. 1-28, October 2000.

[9] P. J. Hu, Y. K. Chau, R. Liu, and K. Y. Tam, "Examining the technology acceptance model using physician acceptance of telememedice technology," Journal of Management Information Systems, vol. 16, no. 2 pp. 91-112, 1999.

[10] venter

[11] I. Nair, “Analysis of Recent Studies Undertaken for Assessing Acceptance of Technology among Teachers using TAM," International Journal of Computer Applications, vol. 32, no. 8, pp. 38-46, 2011.

[12] P. S. Choo and M. K. Rahmat, "Understanding Student Teachers' Behavioural Intention to Use Technology: Technology Acceptance Model (TAM) Validation and Testing," International Journal of Instruction, vol. 6, no. 1, 2013.

[13] I. Isshan, S.F. Bokhare, S. N. Azizan and N. Azman, "Teaching Via Mobile Phones: A Case study on Malaysian Teachers' Technology Acceptance and Readiness," Journal of Educators Online, 2012.

[14] I. Isshan, S.S. Johari and R.M. Idrus, "Acceptance on Mobile Learning via SMS: A Rasch Model Analysis,” iJIM. vol. 4, no. 2, pp. 10,2010 . 
[15] H.H. Chen, M.C. Lee, Y.L. Wu, J. Y. Qiu, C. H. Lin, H. Y. Tang and C.H. Chen, "An Analysis of Moodle in Engineering Education - The TAM Perspective," IEEE International Conference on Teaching, Assessment and Learning For Engineering, 2012.

[16] H.H.Hsu, and Y.Y. Chang, "Extended TAM model: Impacts of convenience on acceptance and use of Moodle," US-China Education Review A. vol. 3, no. 4 pp. 211-218, April 2013.

[17] M. Mabed, and T. Kohler, "The impact of learning management system usage on cognitive and affective performanc," Geneme, October 2012 .

[18] B. Landry, R. Griffeth, and S. Hartman, "Measuring student perception of Blackboard using the Technology Acceptance Model," Decision Sciences Journal of Innovative Education. Vol. 4 no. 1, pp. 87-99, January 2006. http://dx.doi.org/10.1111/j.15404609.2006.00103.x

[19] L. Halawi and R. Mccarthy, "MEASURING FACULTY PERCEPTIONS OF BLACKBOARD USING THE," Issues in Information Systems, vol. VIII, no. 2, pp. 160-165, 2007.

[20] Z.F. Muhsen, A. Maaita, A. Odeh, M. A. Eljinini, A. Nsour, M. A. Azzam and M. Ahed, "Moodle Claroline and Blackboard Systems," European, Mediterranean \& Middle Eastern Conference on Information Systems, June 2012.

[21] G. Ilin, "Moodle: A way for blending VLE and Face-to-face instruction in the ELT Context," TOJET: The Turkish Online Journal of Educaitonal Technology, vol. 12, no. 4 pp. 103-112, October 2013.

[22] M. S. Asiri, R. Mahmud, K. Bakar, and A.F. Ayub, "Factors influencing the use of learning management system in Saudi Arabian Higher Education: A theoretical framework," Canadian Center of Science and Education: Higher Education Studies, vol. 2 no. 2, pp. 125-137, June 2012.

[23] K. Al-Busaidi, and H. Al-Shihi, "Instructors' acceptance of learning management systems: a theoretical framework," Communications of the IBIMA, 2010.

[24] Y. Chen, C. Chen, Y. Lin, and R. Yeh, "Predicting college students' use of e-learning systems: an attempt to extend Technology Acceptance Model," PACIS Proceedings, vol. 2, pp. 172-183, 2007.

[25] L. Nof \& C. Hill, "On The Cutting Edge - A Successful Distance PhD Degree Program: A Case Study," The Internet Journal of Allied Health Sciences and Practice, 3 (2). 2005.

[26] B. Phillips, "Using Online Tools to Foster Holistic, Participatory Recovery: An Educational Approach," The Australian Journal of Emergency Management, 19 (4). 2004.

[27] F. Salajan, A. Welch, C. Peterson, and C. Ray, "Faculty perceptions of teaching quality and peer influence in the utilization of learning technologies: An extension of the Technology Acceptance Model," Proceedings of the International Conference on e-Learning, vol. 2, pp. 335-343, 2012.

[28] H. Elmendorf, \& J. Ottenhoff, "The Importance of Conversation in Learning and The Value of Web-based Discussion Tools." Academic Commons. 2009.

[29] P. Bradford, M. Porciello, N. Balkon \& D. Backus, "The Blackboard Learning System," The Journal of Educational Technology $\begin{array}{lllll}\text { Systems. } & \text { Vol. } 35 & \text { pp. } & 301-314 . & 2007 .\end{array}$ http://dx.doi.org/10.2190/X137-X73L-5261-5656

[30] P. Cote, S. Chen, \& M. Keppell, "New Perspectives in Physical Education: Using Online Learning to Promote Collaborative Critical Thinking," ED-MEDIA 2005 World Conference on Educational Multimedia, Hypermedia and Telecommunication. Montreal, Canada. 2005

[31] R. Vrielink, "Predicting the use of Blackboard and predicting the use of a Personal Digital Analyser with the Technology Acceptance Model. A comparative and a cross-validation research among Dutch pupils aged 12-18," Current Developments in Technology-Assisted Education. Seville m-ICTE 2006. Vol. 1 p. 591595. 2006.

[32] L. Halawi and R. McCarthy, "Measuring Students Perceptions of Blackboard Using The Technology Acceptance Model: A PLS Approach," Issues in Information Systems, vol. IX, no. 2, pp. 95$102,2008$.

[33] I. Abdalla, "Evaluating Effectiveness of E-Blackboard System Using TAM Framework: A Structural Analysis Approach ** In- vited as a paper from E-Learn $2005^{* *}$, vol. 15, pp. 279-287, 2007.

[34] eLearningMinds, "What is Moodle?" UIKnowledge Sdn. Bhd. 2011.

[35] S. Psycharis, G. Chalatzoglidis, and M. Kalogiannakis, "Moodle as a learning environment in promoting conceptual understanding for secondary school students," Eurasia Journal of Mathematics, Science \& Technology Education, vol. 9, no. 1 pp. 11-21, 2013.

[36] A. Diaz, "Teaching Foreign Trade in English Through the Modalities Based on Competences and Using Moodle," Issues in Teachers' Professional Development, vol. 14, no. 2, pp. 163-180, 2012.

[37] E. Zakaria, and Y. Daud, "The role of technology: Moodle as a teaching tool in a graduate Mathematics Education course," Asian Journal of Management Sciences \& Education, Vol. 2 No. 4 October 2013.

[38] M. Holbl and T. Welzer, "Students' Feedback and Communications Habits using Moodle," Electronics and Electrical Engineering, vol. 6, no. 102, pp. 63-66, 2010.

[39] D. Walker, L. Livadas and G. Miles, "Key Influencing Factors Behind Moodle Adoption in Irish Small to Medium Sized Higher Education Colleges," European Journal of Open, Distance and Elearning, 2011.

[40] J. Lin, "Faculty's adoption and implementation of CMS: Moodle case study with survey approach," 2011.

[41] C. Tosun and Y. Taskesenligil, "Using the Moodle Learning Management System in Problem Based Learning Method," International Online Journal of Educational Sciences, 3(3), 2011.

[42] C. K. Chong, C.H. Lee, Y.H. Go, and C.H. Lam, "Factors affecting the usage of WBLE (Web-Based Learning Environment): A Malaysian private university experience," Proceedings of the International Conference on e-Learning, pp. 64-71, 2010.

[43] C. Evans, "The effectiveness of m-learning in the form of podcast revision lectures in higher education," Computers \& Education, vol. 50, pp. 491-498, 2008. http://dx.doi.org/10.1016/ j.compedu.2007.09.016

[44] Z. Unal, and A. Unal, "Evaluating and comparing the usability of web-based course management systems," Journal of Information Technology Education, vol. 10, pp. 19-38, 2011.

[45] M. Prensky, "Digital Natives, Digital Immigrants," On the Horizon, Vol.9 No. 5 2001. http://dx.doi.org/10.1108/ 10748120110424816

[46] A. N. Islam, "The determinants of the Post-Adoption satisfaction of educators with an e-learning system," Journal of Information Systems education, vol. 22, no. 4 pp. 319-330, 2011.

[47] L. Martin, and F. Kellermanns, "A Model of Business School Students' Acceptance of a Web-based Course Management System," Academy of Management Learning and Education, vol. 3, no. $1, \quad$ pp. $7-26, \quad 2004 . \quad$ http://dx.doi.org/10.5465/ AMLE.2004.12436815

[48] L. Soule, B. Kleen, "How to survive transitioning from Blackboard to Moodle : 12 survival tips," Issues in Information Systems, vol. 13, pp. 209-218, 2012.

[49] I. Ismail, S. Bokhare, S. Azizan, and N. Azman, "Teaching via mobile phone: a case study on Malaysian teachers' technology acceptance and readiness," Journal of Educators Online. 2013.

\section{AUTHORS}

W.W.Goh is with the School of Computing and IT, Taylor's University, Malaysia. (e-mail: weiwei.goh@taylors.edu.my).

J.L. Hong, is with the School of Computing and IT, Taylor's University, Malaysia. (e-mail: jerlang.hong@taylors.edu.my).

W. Gunawan was with the School of Computing and IT, Taylor's University, Malaysia. (e-mail: WilsonG@hotmail.com).

Submitted, December, 26, 2013. Published as resubmitted by the authors on June 13, 2014. 